\section{The effect of socio-economic and demographic factors of Turkish provinces on the number of active customers using internet banking}

\author{
İlere ait sosyo-ekonomik ve \\ demografik faktörlerin \\ internet bankacılığını \\ kullanan aktif müşteri \\ sayıları üzerindeki etkisinin \\ incelenmesi
}

\author{
Aykut Arslan ${ }^{1}$
}

\begin{abstract}
Despite the recent improvements in Internet Banking or Online Banking, there are still some constraints, mainly security related issues and some other factors, which contribute to the hesitations of individuals' Internet Banking adoption. Instead of widely used behaviorist models this study utilizes panel data compiled from different sources and explores why Internet Banking is very common in some Turkish provinces but not in the others. The panel data was comprised of the antecedents that were drawn from the relevant literature. To investigate the relationship among the data we employed correlation statistics and to study the Internet Banking adoption differences better among the provinces we used MannWhitney U non-parametric statistical analyses. The results of correlation analysis demonstrate strong relationship among the variables. And the Mann-Whitney U non-parametric test results indicate that the differences of mean ranks are statistically significant. According to these results each of the hypotheses are confirmed significantly.
\end{abstract}

Özet

İnternet bankacıllı̆̆ ya da çevrimiçi (online) bankacilık son ylllarda büyük gelişme göstermişse de kimi araştırmacılar güvenlik başta olmak üzere bir takım etmenler nedeniyle bireylerin internet bankacılluğın benimsemede tereddütler yaşadıklarını iddia etmektedirler. Araştırmamız yaygin olarak uyarlanan davranışsal modeller yerine farklı kaynaklardan derlenmiş panel verileri baz alan bir model kullanarak internet bankacıllğının neden bazı illerde daha yaygin ve neden diğerlerinde daha az kullanıldığı konusunu irdelemektedir. Panel verilerdeki değisskenler ilgili yazından uyarlanmıştır. Veriler arasında bir ilişki olup olmadığını incelemek için korelasyon istatistiği kullanılmış ve iller arasında internet bankacıllğını kullanan bireylerin sayısındaki farklılıkları istatistiksel olarak daha iyi irdeleyebilmek için de Mann-Whitney U parametrik olmayan analizler yapılmıştır. Yapılan korelasyon analizi ile değişkenler arasındaki ilişkinin güçlü olduğu sonucuna ulaşılmıştır. Mann-Whitney U analizleri sonucunda ise sira farklarının istatistiksel olarak anlamlı oluğu görülmektedir. Buna göre her

\footnotetext{
${ }^{1}$ Yrd.Doç.Dr., Haliç Üniversitesi, İşletme Fakültesi, İngilizce İşletme Bölüm Başkanlığı, aykutarslan@halic.edu.tr
} 
Arslan, A. (2012). İllere ait sosyo-ekonomik ve demografik faktörlerin internet bankacilığını kullanan aktif müssteri sayllan üzerindeki etkisinin incelenmesi. International Journal of Human Sciences [Online]. (9)2, 288-302.

Keywords: e-Banking; Internet Banking; Online Banking; Turkey

Extended English Abstract

hipotezimiz istatistiksel olarak

desteklenmektedir.

Keywords e-bankacilık; internet bankacıllı̆g, çevrimiçi bankacılık, Turkiye

\section{Giriş}

İnternetin her alanda olduğu gibi bankacllık sektöründe de alternatif bir hizmet kanalı olarak (Korkmaz ve Gövdeli, 2004) yaygın bir şekilde kullanılmaya başlanması özellikle bankalar açısından düşük maliyet-yoğun hizmet imkânını da beraberinde getirmiştir. Kurumsal açıdan müşteri odaklılı̆̆ının artması, şube, personel ve kira giderlerinde azalma, ürün yeniliği ve çeşitliği, pazarlama ve iletişim, coğrafi bölgeye ve zamana bağlı kalınmaksızın hizmet sunmak gibi avantajları olabilmektedir (Mermod, 2011, Pala ve Kartal, 2010, Sullivan ve Wang, 2005). Türkiye’de bugün internet bankacıllğı, herhangi bir banka şubesinin sağlayacağı hizmetlerin hemen hepsinden, zaman ve mekândan bağımsız olarak çabuk ve kolayca yararlanabilmeyi sağlayabilmektedir. İnternet bankacıllı̆ını 7 gün 24 saat, internet erişimine sahip herhangi bir bilgisayar aracıllğıyla dünyanın her yerinden kullanabilmektedir (http://www.kobifinans.com.tr/tr/bilgi merkezi/02090405/9946).

14 Temmuz 2012 tarihi itibari ile Facebook gibi bir sosyal medya kullanımında 31.112.380 kişi ile dünyada altıncı sırada (http://www.socialbakers.com/facebook-statistics/) yer alan Türkiye'de, bireylerin Internet bankacılığının nimetlerinden yararlanma düzeyleri nispeten düşük olarak kabul edilmektedir (Pala ve Kartal, 2010, Socialmediatr.com, 2011). Oysa Mart 2011 tarihi itibariyle internet bankacıllğı yapmak üzere sistemde kayıtlı olan ve en az bir kez giriş işlemi yapmış toplam bireysel müşteri sayısının 16.3 milyon ulaştığı(bireysel banka müşterilerinin yaklaşık \%40’1) belirtilmektedir (DT22, 2011). Bu konuda bireylerin internet bankacıllğını neden kullanıp kullanmadığı konusunda yapılan görgül araştırmaların neredeyse tamamı davranışsal etkenler (bireysel tercihle, bir takım psikolojik faktörler, yeni teknolojilere karşı tutumlar vb.) üzerinde yoğunlaşmaktadır (Gounaris ve Koritos, 2008). Bu kapsamda değişik kriterlere göre seçilen örneklemlerdeki bireylere anketler uygulanarak ve özellikle Teknoloji Kabul Modelleri (TAM), Birleştirilmiş Teknoloji Kullanım ve Kabul Modelleri (UTAUT), Planlı Davranış Teorileri (TRA) ve Yenilik Yayılması (DT) gibi geçerliliği ve güvenirliği pek çok kez kanıtlanmış modeller yaygın olarak kullanılmaktadır (Bakınız Akhlaq ve Shah , 2011, AL-Majali ve Mat, 2011, Gounaris ve Koritos, 2008, Mangin vd., 2011, Qurashi vd., 2008, Reid ve Levy, 2008) .

Ancak bütün bu araştırmalarda kullanılan örneklem büyüklükleri ile tüm ülkeyi veya en azından bir ili aç1klamaya yetecek genellemeler yapmak pek mümkün gözükmemektedir (Toy ve Tosunoğlu, 
Arslan, A. (2012). İllere ait sosyo-ekonomik ve demografik faktörlerin internet bankacilığını kullanan aktif müssteri sayllan üzerindeki etkisinin incelenmesi. International Journal of Human Sciences [Online]. (9)2, 288-302.

2007). Araştırmamız yazındaki bu boşluğu doldurabilmek amacıyla illere ait sosyo-ekonomik ve demografik faktörlerin Internet bankacıllğını kullanan aktif müşteri sayıları üzerindeki etkisini ortaya koymayı amaçlamaktadır. Bunun için Türkiye Bankalar Birliğinin web sitesinde yayımlanan panel veriler ile Yıldız vd., (2010) tarafından güncel veriler ve TÜIKK verileri kullanılarak illerin sosyoekonomik gelişmişlik sıralamasına ait göstergeler kullanılmıştır. Veriler arasında bir ilişski olup olmadığını analiz etmek için korelasyon istatistiği kullanılmış ve neden-sonuç ilişkisini ölçebilmek için de regresyon analizi yapılmıştır.

\section{Türkiye'de Internet Bankacılığının Mevcut Durumu}

Türkiye Bankalar Birliği istatistiklerine göre (DT22 (2011), internet bankacıllğ1 yapmak üzere sistemde kayıtlı olan ve en az bir kez giriş işlemi yapmış toplam bireysel müşteri sayısı, Haziran 2011 itibariyle, 16,7 milyon olmuştur. Son bir yıl içerisinde en az bir kez giriş işlemi yapmış toplam bireysel müşteri sayısı ise 8,8 milyon kişidir. İşlemler açısından incelendiğinde Nisan-Haziran 2011 döneminde internet bankacıllğı ile gerçekleştirilen 11 milyon adet yatırım işleminin hacim bakımından 87,5 milyar TL 'ye ulaştı̆̆1 görülmektedir. Yine aynı dönem içerisinde internet bankacılığı hizmeti kullanılarak yapılan yatırım işlemleri dışındaki finansal işlemlerin toplam adedinin 80 milyona, tutarının ise 282 milyar TL olduğu; EFT, havale ve döviz transferi işlemlerini kapsayan para transferleri işlemleri yatırım işlemleri dışındaki finansal işlem hacminin yüzde 85'ini oluşturduğu gözlemlenmektedir (ibid).

Diğer ülkelerin kullanım oranlarını karşılaştırdığımızda Kanada'daki internet kullanıcılarının \%64,8'inin internet bankacillğı hizmetini kullandığı ve dünyada lider konumunda bulunduğu görülmektedir (Socialmediatr.com, 2011). Hollanda \%60,7’lik oranla ikinci durumdayken sırasıyla \%56,6 oranı ile Fransa, \%53,9 oranı ile İsveç ve \%51,1 ile İngiltere dünyada internet bankacıllı̆ını en çok kullanan ülkeler olarak başı çekmektedirler. Aynı sitede bu alanda dünyadaki ilk 10 ülkenin tamamının, bireylerin banka hesabının bulunma olasıllğı daha yüksek olan ve düzenli internet kullanım oranının yüksek olduğu ülkelerden oluştuğuna da dikkat çekilmektedir. Türkiye'de bu oran 2010 y1l itibari yalnızca \%16,8'dir (BTİ, 2011).

\section{Kuramsal Çerçeve ve Hipotezler}

Kimi araştırmacılar (Gurau, 2001, Atay, 2008, Kang, 2009) iyi bir Bilgi ve İletişim Teknolojisi altyapısının bir ülkede neredeyse tüm sosyal ve ekonomik hayatın her kademesinde bilişim teknolojilerini kullanımını teşvik edici bir etmen olabileceğini öne sürmektedir. Bu bağlamda internete bağlı bilgisayara sahip olma oranı arttıkça internet bankacıllğı ve e-ticaret kullanımı da artma eğilimi göstermektedir (Kang, 2009). Benzer bulguyu Li ve Worthington (2004)'da savunmuşlar ve 27 ülkenin bilişim altyapısı ve e-bankacıllk arasındaki ilişkiyi incelediklerinde 
Arslan, A. (2012). İllere ait sosyo-ekonomik ve demografik faktörlerin internet bankacilığını kullanan aktif müşteri sayllan üzerindeki etkisinin incelenmesi. International Journal of Human Sciences [Online]. (9)2, 288-302.

istatistiksel olarak olumlu bir ilişkinin varlığına işaret etmişlerdir. Adapa (2011) e-bankacilığın (internet bankacılığ1 ve mobil bankacılık) ülke çapında yaygınlaşmasında etken faktörün internet penetrasyonu olduğunu iddia etmekte ve teknolojik altyapıları iyi olan gelişmiş ülkeleri örnek göstermektedir. Yüksek gelir düzeyine sahip bireylerin yine yüksek internet erişimine ve bilgisayar sahipliğine dikkat çekmektedir. Diğer yandan Biswas vd. (2011) Bangledeş’te yaptıkları bir araştırmada e-bankacıllğın başarısı için ön koşullardan biri olarak pazar büyüklüğünü öne sürmüşler ve buna gerekçe olarak da yatırımların ekonomik açıdan sürdürülebilirliğinin pazara bağlı olmasını göstermişlerdir. Bu bağlamda ülke nüfusunun büyüklüğü önem taşımaktadır. Ancak bu nüfusun web sitesini kullanabilmesi için en azından okur-yazar olması ve bankacıllk işlemlerinde kullanabilmeleri için uygun ve düzenli bir gelirlerinin de olması gerekmektedir. Yani uygun bir sosyo-ekonomik düzeyin önemine atıfta bulunmaktadırlar.

Gurau (2001) Romanya'da 300 kişi ile gerçekleştirdiği bir araştırmada kurumsal kullanıcıların (işyerleri) ve bilişim altyapısının e-banka kullanımına doğrudan etki ettiğini ancak cinsiyet, yaş ve internet kullanım bilgisinin kısmen etkilediğini ileri sürmüştür. Taylor Nelson Sofres Piar tarafından (TNSP, 2003) yapılan bir araştırmada bankaların alternatif dağııım kanallarındaki (ATM, telefon bankacıllğ̣ ve internet bankacılluğ1) müşteri dağılımı incelenmiş ve 1.036 kişiden oluşan örneklemde ağırlıklı müşteri gruplarının B (Orta yönetici) ve C (Genç yönetici) segmentlerinden oluştuğu ve erkeklerin ve 25-30 yaş grubunun bu kanalları daha çok kullandığı sonuçlarına ulaşılmıştır. Altan ve Karasioğlu (2004)'nun 298 kişilik bir örneklem üzerinde yaptıkları bir araştırmada erkeklerin kadınlardan, gençlerin orta yaş ve üzerindekilerden, geliri ve eğitim düzeyi yüksek olanların düşük olanlardan internet bankacıllğını daha fazla kullandığına dair bulgular elde edilmiştir. 2005 yılında Amerikalı akademisyenlerin (Adapa, 2011) 4442 hane halkı ile yapılan bir araştırma verileri üzerinde yaptıkları bilimsel çalışmada yaş ve yüksek eğitimin internet bankacıllı̆ı tercihinde rol oynayabileceğini ortaya koymaktadır. Gounaris, ve Koritos (2008) davranışsal model ile demografik etmenlerin etken olabileceği bir model ile internet bankacıllğını kullanan 858 kişi ve kullanmayan 418 kişi üzerinde Yunanistan'da bir çalışma yürütmüşler ve özellikle meslek ile eğitim değişkenlerinin kullanım tercihleri üzerinde belirgin bir etki yaptığı sonucuna ulaşmışlardır. 2010 yllında 527 kişilik bir örneklem ile Türkiye'de yapılan bir araştırmada (Boyacıoğlu vd., 2010) davranışsal etmenlerin yanında cinsiyet, yaş, meslek, eğitim ve gelir durumu gibi değişkenlerin internet bankacıllğı kullanımında etkili olduğu iddia edilmektedir. Yakın zamanda Türkiye'de yapılan ve 860 kişinin katıldı̆̆ı bir araştırmada ise (Mermod, 2011) yaş ve cinsiyet ile internet bankacılluğ1 kullanımı arasında istatistiksel bir bulguya rastlanılmadığı ancak eğitim düzeyi ve gelir ile kullanım arasında olumlu bir ilişkinin olduğu gözlemlenmiştir. 
Arslan, A. (2012). İllere ait sosyo-ekonomik ve demografik faktörlerin internet bankacıllğını kullanan aktif müşteri sayılan üzerindeki etkisinin incelenmesi. International Journal of Human Sciences [Online]. (9)2, 288-302.

E-ticaret göstergelerinde artış internette işlem yapma alışkanlı̆̆ının bir göstergesi olarak ele alınabilir. Kim, Widdows ve Yilmazer (2005) ABD'li tüketicilerle yaptıkları araştırmada bankaların sundukları teknolojik yenilikleri daha önce kullanan ve bunlara aşina olan bireylerin internet bankacıllğını da en çok tercih eden grup olduklarını belirtmektedir. Modelimizdeki bağımsız değişkenlerden biri de illerdeki sanal iş yerleri sayılarıdır. Sanal alısverişe aşina olan bireylerin internetten sunulan hizmetlere daha yatkın ve kullanma eğiliminde olduklarını varsayıyoruz. Aynı şekilde e-ticaret işletmelerinin anatomileri gereği internet üzerinden her türlü ticari işleme yatkın oldukları da kabul edilebilir. 2010 yılına ait Bilgi Toplumu İstatistikleri verilerinde işletmelerin internet bankacılı̆̆1 kullanımının bireylere göre daha yüksek olduğu görülmektedir. İnternet erişimine sahip girişimlerin $\% 78,1$ ’ $\mathrm{i}$ interneti bankacıllk ve finansal hizmetler için kullanırken bireylerin yalnızca \%16,8'i kullanmaktadır (BTI, 2011).

\section{Hipotezler}

H1. Sosyo-ekonomik gelişmişlik düzeyi daha yüksek olan illerin internet bankacıllı̆ını kullanan aktif müşteri sayıları, düşük olanlardan daha fazladır.

H2. 30 yaş altı erkek nüfusu $(>15<30)$ daha çok olan illerin internet bankacıllğını kullanan aktif müssteri sayıları, az olanlardan daha fazladır.

H3. Genç nüfusu $(>15<30)$ daha çok olan illerin internet bankacıllğı̆nı kullanan aktif müşteri sayıları, az olanlardan daha fazladır.

H4. Sanal işyeri sayısı daha çok olan illerin internet bankacılı̆̆ını kullanan aktif müşteri sayıları, az olanlardan daha fazladir.

H5. Geniş bant internet abone sayıları daha çok olan illerin internet bankacılluğını kullanan aktif müşteri sayıları, az olanlardan daha fazladır.

H6. Lise ve üstü eğitimli nüfusu daha çok olan illerin internet bankacıllğını kullanan aktif müşteri sayıları, az olanlardan daha fazladır.

\section{Araştırma Yöntemi}

Araştırmamızda kullanılan bağımlı değişken Türkiye Bankalar Birliğinin belirli dönemlerde yayımladığı verilerden derlediğimiz ve Haziran 2011 y1lı internet bankacıllğını kullanan aktif müşteri sayılarından oluşmaktadır. Bağımsız değişkenlere ait panel veriler ise PCA analizi kullanılarak sosyal ve ekonomik alanlardan seçilen toplam 41 değişkenin (Tablo-1) dâhil edildiği bir hesaplama sonucu bulunmuştur (Yıldız vd., 2010). Burada esas amaç Türkiye'nin bölgeleri ve illeri arasındaki sosyo-ekonomik gelişme sürecindeki geniş sosyo-ekonomik farklllıkları mümkün olduğunca yansitabilmektir. 
Arslan, A. (2012). İllere ait sosyo-ekonomik ve demografik faktörlerin internet bankacılığını kullanan aktif müşteri sayılan üzerindeki etkisinin incelenmesi. International Journal of Human Sciences [Online]. (9)2, 288-302.

Tablo-1: Araştırmada Kullanılan Değişkenler

\begin{tabular}{|c|c|c|c|c|c|c|c|}
\hline İL & IB & $\begin{array}{c}\text { Sos-eko. } \\
\text { index }\end{array}$ & $\begin{array}{c}\text { Erkek } \\
\text { Nüfus } \\
(>15<30) \\
\end{array}$ & $\begin{array}{c}\text { Genç } \\
\text { Nüfus } \\
(>15<30) \\
\end{array}$ & $\begin{array}{l}\text { Sanal } \\
\text { İşyeri } \\
\text { Sayıs1 } \\
\end{array}$ & $\begin{array}{c}\text { Genişbant } \\
\text { Abone } \\
\text { Sayiları } \\
\end{array}$ & $\begin{array}{c}\text { Eğitimli } \\
\text { Nüfus } \\
\text { (Lise ve üstü) }\end{array}$ \\
\hline Adana & 125571 & 2,6245 & 536114 & 74,13 & 435 & 446238 & 480405 \\
\hline Adiyaman & 17024 & $-3,8313$ & 169352 & 79,69 & 89 & 30194 & 83623 \\
\hline Afyonkarahisar & 35676 & $-0,3938$ & 170717 & 57,92 & 282 & 59260 & 104987 \\
\hline Ağn1 & 13558 & $-6,5364$ & 116211 & 83,37 & 59 & 22751 & 46917 \\
\hline Aksaray & 17297 & $-1,4828$ & 97251 & 75,27 & 94 & 36395 & 52380 \\
\hline Amasya & 19488 & 0,0346 & 85748 & 64,17 & 105 & 76310 & 63386 \\
\hline Ankara & 742141 & 13,3247 & 876227 & 70,1 & 3,859 & 846942 & 1746813 \\
\hline Antalya & 222773 & 5,1158 & 409668 & 75,39 & 1,004 & 155252 & 449403 \\
\hline Ardahan & 4156 & $-4,746$ & 27474 & 68,12 & 33 & 11675 & 12799 \\
\hline Artvin & 10932 & $-0,2353$ & 37178 & 65,4 & 81 & 20280 & 31954 \\
\hline Aydın & 68464 & 2,261 & 229793 & 63,75 & 417 & 140438 & 182917 \\
\hline Balıkesir & 82653 & 2,1406 & 210394 & 61,68 & 444 & 72281 & 223989 \\
\hline Bartun & 11514 & $-1,47$ & 35840 & 63,24 & 55 & 9197 & 22196 \\
\hline Batman & 16196 & $-4,1247$ & 145828 & 85,85 & 60 & 80739 & 70174 \\
\hline Bayburt & 3255 & $-3,0414$ & 18029 & 72,75 & 25 & 5261 & 13505 \\
\hline Bilecik & 15833 & 2,7733 & 41550 & 71,33 & 78 & 34661 & 49422 \\
\hline Bingöl & 7704 & $-5,7479$ & 77181 & 83,42 & 51 & 30851 & 36964 \\
\hline Bitlis & 9989 & $\begin{array}{l}-5,9739 \\
\end{array}$ & 95968 & 83,86 & 58 & 21509 & 41107 \\
\hline Bolu & 23092 & 3,6312 & 64399 & 63,29 & 131 & 13039 & 58585 \\
\hline Burdur & 16934 & 2,2574 & 53251 & 64,9 & 127 & 28343 & 46560 \\
\hline Bursa & 238578 & 5,795 & 639669 & 73,87 & 866 & 169678 & 661610 \\
\hline Çanakkale & 39848 & 2,6545 & 103878 & 59,29 & 186 & 62256 & 94313 \\
\hline Çankırı & 9568 & $-0,9061$ & 34235 & 59,4 & 90 & 15353 & 33323 \\
\hline Çorum & 25307 & $-1,1268$ & 102874 & 66,99 & 153 & 43033 & 85435 \\
\hline Denizli & 75270 & 3,4636 & 218825 & 67,31 & 408 & 66416 & 186221 \\
\hline Diyarbakır & 50259 & $-3,7639$ & 449311 & 93,21 & 171 & 271078 & 217727 \\
\hline Düzce & 21685 & $-0,1387$ & 80509 & 70,33 & 113 & 34873 & 54932 \\
\hline Edirne & 28889 & 2,9301 & 74015 & 65,48 & 176 & 30678 & 91965 \\
\hline Elazı̆̆ & 27271 & $-0,8997$ & 147071 & 65,7 & 161 & 26054 & 116123 \\
\hline Erzincan & 12359 & $-1,2898$ & 50508 & 76,61 & 100 & 18563 & 42600 \\
\hline Erzurum & 38280 & $-2,5724$ & 214747 & 80,77 & 190 & 61513 & 145622 \\
\hline Eskişehir & 75959 & 5,4807 & 191926 & 71,04 & 297 & 75330 & 256269 \\
\hline Gaziantep & 82866 & 0,4191 & 316965 & 76,73 & 264 & 180911 & 249074 \\
\hline Giresun & 19426 & $-1,607$ & 96581 & 66,58 & 151 & 112214 & 79298 \\
\hline Gümüşhane & 5583 & $-2,8523$ & 34055 & 67,68 & 51 & 26545 & 23176 \\
\hline Hakkari & 9278 & $-6,4263$ & 82208 & 86,4 & 30 & 12354 & 39400 \\
\hline Hatay & 73755 & 0,287 & 340256 & 76,95 & 247 & 97066 & 179557 \\
\hline Iğdır & 5515 & $-4,8515$ & 52015 & 84,43 & 34 & 24743 & 23550 \\
\hline Isparta & 33113 & 3,0835 & 124013 & 71,13 & 181 & 53926 & 97999 \\
\hline İstanbul & 2355931 & 17,1245 & 3468205 & 82,49 & 10,692 & 851476 & 3840876 \\
\hline İzmir & \begin{tabular}{|l|}
452755 \\
\end{tabular} & 9,2423 & 980823 & 72,15 & 1,878 & 836443 & 1161519 \\
\hline Kahramanmaraş & 43036 & $-1,7012$ & 227830 & 78,67 & 161 & 96512 & 148488 \\
\hline Karabük & 17585 & 1,3401 & 51799 & 66,31 & 86 & 19475 & 51116 \\
\hline Karaman & 13676 & 0,9203 & 40210 & 78,34 & 61 & 16174 & 39877 \\
\hline Kars & 11847 & $-4,9092$ & 83267 & 81,32 & 62 & 23953 & 39567 \\
\hline Kastamonu & 22695 & $-0,3892$ & 81099 & 64,05 & 170 & 20788 & 57810 \\
\hline Kayseri & 80925 & 2,4042 & 273236 & 70,94 & 345 & 71106 & 284908 \\
\hline Kurıkkale & 15033 & 0,754 & 69423 & 70,2 & 75 & 44434 & 73494 \\
\hline Kırklareli & 23441 & 3,0434 & 75240 & 65,23 & 124 & 12142 & 78038 \\
\hline Kırşehir & 9609 & $-0,2598$ & 54331 & 76,98 & 54 & 18792 & 48552 \\
\hline Kilis & 4590 & $-2,4608$ & 32004 & 78,93 & 14 & 8035 & 18131 \\
\hline
\end{tabular}


Arslan, A. (2012). İllere ait sosyo-ekonomik ve demografik faktörlerin internet bankacıllğını kullanan aktif müşteri sayılan üzerindeki etkisinin incelenmesi. International Journal of Human Sciences [Online]. (9)2, 288-302.

\begin{tabular}{|l|l|c|c|c|c|c|c|} 
Kocaeli & 180453 & 8,5219 & 342408 & 79,81 & 463 & 83362 & 426563 \\
\hline Konya & 130511 & 2,0486 & 514606 & 71,88 & 558 & 265617 & 359236 \\
\hline Kütahya & 36033 & 0,3115 & 141484 & 69,73 & 166 & 98847 & 108650 \\
\hline Malatya & 32758 & $-0,9008$ & 161042 & 70,82 & 180 & 79150 & 155588 \\
\hline Manisa & 67926 & 1,8884 & 363377 & 75,27 & 320 & 82512 & 225147 \\
\hline Mardin & 23479 & $-5,3043$ & 213862 & 83,48 & 100 & 51181 & 81349 \\
\hline Mersin & 100974 & 2,1565 & 345977 & 71,69 & 349 & 137512 & 345635 \\
\hline Muğla & 101464 & 3,678 & 181456 & 69,84 & 818 & 152962 & 127622 \\
\hline Muş & 10224 & $-6,6496$ & 118701 & 90,66 & 41 & 25371 & 32214 \\
\hline Nevşehir & 17309 & $-0,2616$ & 66263 & 70,75 & 117 & 29645 & 44054 \\
\hline Niğde & 17327 & $-1,5252$ & 72985 & 78,27 & 70 & 33735 & 50421 \\
\hline Ordu & 29030 & $-2,4979$ & 164413 & 66,59 & 185 & 33554 & 111771 \\
\hline Osmaniye & 17065 & $-1,1892$ & 120692 & 75,51 & 76 & 47307 & 87890 \\
\hline Rize & 22026 & 0,1379 & 75713 & 73,07 & 150 & 22584 & 61319 \\
\hline Sakarya & 66350 & 1,7031 & 147719 & 67,77 & 350 & 41020 & 182219 \\
\hline Samsun & 65930 & 0,5417 & 307704 & 66,89 & 313 & 146781 & 236189 \\
\hline Siirt & 10707 & $-5,1654$ & 86109 & 86,98 & 181 & 23331 & 37890 \\
\hline Sinop & 10733 & $-1,1215$ & 44820 & 60,44 & 57 & 12003 & 32316 \\
\hline Sivas & 31791 & $-0,4488$ & 177577 & 68,9 & 74 & 52111 & 128545 \\
\hline Şanliurfa & 39449 & $-4,6074$ & 399898 & 81,38 & 53 & 95679 & 117087 \\
\hline Șırnak & 18333 & $-6,3983$ & 127454 & 88,4 & 194 & 30584 & 44305 \\
\hline Tekirdağ & 68540 & 3,5553 & 169832 & 76,24 & 256 & 66141 & 173510 \\
\hline Tokat & 27490 & $-1,8371$ & 155130 & 66,89 & 141 & 54139 & 96367 \\
\hline Trabzon & 46991 & 0,1402 & 191338 & 62,82 & 288 & 0 & 145369 \\
\hline Tunceli & 7799 & $-2,8327$ & 16574 & 66,8 & 50 & 4145 & 23494 \\
\hline Uşak & 20546 & 1,1997 & 78896 & 64,88 & 93 & 71041 & 63493 \\
\hline Van & 27399 & $-5,8239$ & 304707 & 85,36 & 105 & 123331 & 94844 \\
\hline Yalova & 17619 & 2,6408 & 40181 & 67,7 & 100 & 9902 & 44015 \\
\hline Yozgat & 18813 & $-2,7304$ & 67967 & 70,84 & 123 & 155064 & 68999 \\
\hline Zonguldak & 44921 & 1,4035 & 149744 & 71,66 & 197 & 149022 & 94392 \\
\hline & & & & & & & \\
\hline
\end{tabular}

KAYNAK: Yıldız vd. (2010), TÜİK(2011), DT22 (2011), IpsosKMG (2010)

İllere ait nüfus ile ilgili tüm veriler TÜİK sayfasından; sanal işyeri sayıları Türkiye Bankalar Birliği verilerinden (DT22, 2011); geniş bant Internet abone yüzdeleri Ipsos KMG tarafından Nisan 2010'da raporlanan PC ve İnternet Penetrasyonu verilerinden (IpsosKMG, 2010) elde edilmiştir. Yüzde olarak sunulan veriler il toplam nüfusa oranlanıp bireysel genişbant abone sayıları yaklaşık olarak hesaplanmıştır. Genç yaş nüfus aralı̆̆1 her ne kadar 15-24 yaş olarak kabul edilse de son zamanlarda yapılan pek çok uluslararası çalışma ve istatistikte genç yaş grubu 15-29 olarak kullanılmaya başlanmıştır (Yentürk ve Başlevent, 2007).

Veriler arasında bir ilişki olup olmadığını incelemek için korelasyon istatistiği kullanılmış ve iller arasında internet bankacıllğını kullanan bireylerin sayısındaki farklılıkları istatistiksel olarak daha iyi irdeleyebilmek için de Mann-Whitney U parametrik olmayan testler kullanılmıştır. 
Arslan, A. (2012). İllere ait sosyo-ekonomik ve demografik faktörlerin internet bankacıllğını kullanan aktif müşteri sayılan üzerindeki etkisinin incelenmesi. International Journal of Human Sciences [Online]. (9)2, 288-302.

\section{Analizler}

\section{Korelasyon Analizi}

Tablo 2'deki korelasyon katsayılarına bakılacak olunursa, incelenen değişkenler arasında en fazla \%1 hata payıyla anlamlı ve güçlü bire bir ilişkiler olduğu görülmektedir. Değişkenlerden sosyoekonomik gelişmişlik düzeyi ile internet bankacılı̆̆ını kullanan aktif müşteri sayıları birbirleri ile güçlü bir şekilde (r:0675**) ilişkilidirler. Aynı şekilde geniş bant abone sayıları ile internet bankacıllğını kullanan aktif müşteri sayıları arasında da güçlü bir ilişkinin (r:0,788**) olduğu söylenebilir. Sanal iş yeri sayısı ile internet bankacıllğını kullanan aktif müşteri sayıları birbirleri ile çok güçlü bir şekilde ilişkilidirler $\left(r: 0,914^{* *}\right)$. Son olarak lise ve üstü eğitimli nüfus sayısı ile internet bankacıllğını kullanan aktif müşteri sayıları arasındaki ilişki düzeyini incelediğimizde korelasyonun oldukça yüksek hatta en yüksek korelasyon oranının bu değissken için bulunduğu sonucu çıkarılabilir $\left(r: 0,963^{* *}\right)$.

Tablo 2. Korelasyon Tablosu (Spearman's rho)

\begin{tabular}{lllllll}
\hline & $\mathbf{1}$ & $\mathbf{2}$ & $\mathbf{3}$ & $\mathbf{4}$ & $\mathbf{5}$ & $\mathbf{6}$ \\
\hline (1) IB & 1.000 & & & & \\
\hline (2)Socio_eco & $.675^{* *}$ & 1.000 & & & \\
\hline (3) Broadband & $.788^{* *}$ & $.385^{* *}$ & 1000 & & \\
\hline (4) Online_Firms & $.914^{* *}$ & $.685^{* *}$ & $.686^{* *}$ & 1.000 & \\
\hline (5) Age_k30 & $.870^{* *}$ & $.319^{* *}$ & $.814^{* *}$ & $.757^{* *}$ & 1.000 & \\
\hline (6) Egitim & $.963^{* *}$ & $.600^{* *}$ & $.818^{* *}$ & $.862^{* *}$ & $.912^{* *}$ & 1000 \\
\hline
\end{tabular}

$N=81 . p<0.01,{ }^{* *} \cdot p<0.05^{*}$

\section{Hipotez Testleri}

Parametrik olmayan verilerin sinanmasında kullanılan Mann-Whitney U istatistiği iki bağımsız örneklemin sıra ortalamalarının farklılığını incelemektedir. T-testinin parametrik olmayan karşıllğıdır ve normal dağılım göstermeyen verilerin analizinde kullanılır. Buna göre illere ait veri setimizde yer alan her grubun ortancaları alınmış ve her set kendi içerisinde iki gruba ayrılmıştır (Düşük-Yüksek veya Az-Çok). Hangi grubun internet bankacıllğı üzerinde ne kadar etkisi olduğu ve aralarındaki bu etki farkının istatistiksel sınamaları Tablo 3’te verilmiştir. Buna göre birinci hipotezin doğrulanması için iller sosyo-ekonomik gelişmişlik düzeylerine göre iki gruba ayrıldı (Düşük ve Yüksek). Sosyoekonomik gelişmişlik düzeyi daha yüksek olan grubun $(\mathrm{N}=40)$ internet bankacıllı̆ını da daha fazla kullanan grup olduğu ve gruplar arasındaki farkın istatistiksel açıdan da anlamlı olduğu söylenebilir 
Arslan, A. (2012). Illere ait sosyo-ekonomik ve demografik faktörlerin internet bankacilığını kullanan aktif müşteri sayllan üzerindeki etkisinin incelenmesi. International Journal of Human Sciences [Online]. (9)2, 288-302.

( $Z=-5,337, p=.000)$. İkinci hipotezin analizinde illerdeki 15-29 yaş arası yaş gruplarında erkek nüfusu az ve çok olanlar için sıra ortalamaları arasındaki farkın istatistiksel olarak anlamlı olup olmadığı irdelenmiştir. Buna göre 30 yaş altı erkek nüfusu fazla olan illerdeki $(N=40)$ internet bankacıllğını kullanan aktif müşteri sayılarının az olanlara kıyasla daha fazla olduğu ve gruplar arasındaki farkın istatistiksel açıdan da anlamlı olduğu anlaşılmaktadır $(Z=-7,000, p=.000)$. Üçüncü hipotezin sınanması için illerdeki genç nüfus sayıları (15-29) çok ve az olanların internet bankacıllğını kullanan aktif müşteri sayılarının sıra ortalamaları karşılaştırılmıştır. Analiz sonucuna göre genç nüfusu çok olan illerin $(\mathrm{N}=40)$ internet bankacilı̆ 1 kullanımı az olanlardan daha fazladır ve bu fark istatistiksel olarak anlamlıdır $(Z=-7,123, p=.000)$. Dördüncü hipotez testinde sanal işyeri sayısı çok veya az olan illerdeki internet bankacıllğı kullanımlarına bakılmış ve aralarındaki farkın anlamlı olup olmadığı sınanmıştır. Analiz sonucu sanal işyeri çok olan illerin $(\mathrm{N}=40)$ internet bankacıllğını kullanan aktif müşteri sayılarının az olanlara kıyasla daha fazla olduğu ve bu farkın istatistiksel olarak da anlamlı bulunduğu anlaşılmaktadır $(Z=-6,981, p=.000)$. Beşinci hipotezde geniş bant abone sayıları çok veya az olan illerin internet bankacıllğı kullanımına ait sıra ortalamaları farkları incelenmiştir. Buna göre geniş bant abone sayısı çok olan illerin $(\mathrm{N}=40)$ internet bankacıllı̆ını kullanan aktif müşteri sayıları da abone sayısı az olan illere göre daha fazladır ve bu fark istatiksel olarak da anlamlıdır $(Z=$ $-6,550, p=.000)$. Son olarak altıncı hipotez sınanmış ve illerdeki lise ve üstü eğitimli nüfusu az veya çok olanların internet bankacılı̆̆ kullanımlarına bakılmıştır. Lise ve üstü eğitimli nüfusu daha çok olan illerin ( $=40)$ internet bankacıllğını kullanan aktif müşteri sayıları, daha az olanlardan çok daha yüksektir ve sıra ortalamaları arasındaki bu fark istatistiksel olarak da anlamlı bulunmuştur $(Z=$ $7,595, p=.000)$.

Tablo 3 Hipotezler için Mann-Whitney U Test Sonuçları (N=81)

\begin{tabular}{|c|c|c|c|c|}
\hline Hipotezler & $\mathbf{N}$ & $\begin{array}{l}\text { Sira } \\
\text { Ort. }\end{array}$ & Z Score & $\mathbf{P}$ \\
\hline $\begin{array}{l}\text { 1. Sosyo-ekonomik gelişmişlik düzeyi daha yüksek olan illerin Düşük } \\
\text { internet bankacılı̆ını kullanan aktif müşteri sayıları, düşük } \\
\text { olanlardan daha fazladır. }\end{array}$ & 41 & 27.22 & $-5,337$ & .000 \\
\hline
\end{tabular}

\begin{tabular}{llllll} 
& Yüksek & 40 & 55.13 & \\
\hline $\begin{array}{l}\text { 2. } 30 \text { yaş altı erkek nüfusu (>15 < 30) daha çok olan illerin } \\
\text { internet bankacıllğını kullanan aktif müşteri sayılart, az }\end{array}$ & Az & 41 & 22.93 & $-7,000$ & .000 \\
olanlardan daha fazladir. & & & & &
\end{tabular}

\begin{tabular}{llllll} 
& Çok & 40 & 59.53 & \\
\hline 3. Genç nüfusu $(>\mathbf{1 5}<\mathbf{3 0})$ daha çok olan illerin internet & $\mathrm{Az}$ & 41 & 22.61 & $-7,123$ & .000 \\
bankacılığını kullanan aktif müşteri sayılant, az olanlardan & & & & &
\end{tabular}


Arslan, A. (2012). Illere ait sosyo-ekonomik ve demografik faktörlerin internet bankacilığını kullanan aktif müşteri sayllan üzerindeki etkisinin incelenmesi. International Journal of Human Sciences [Online]. (9)2, 288-302.

daha fazladir.

\begin{tabular}{llllll} 
& Çok & 40 & 59.85 & \\
\hline $\begin{array}{l}\text { 4. Sanal işyeri sayısı daha çok olan illerin internet bankacılı̆̆ını } \\
\text { kullanan aktif müşteri sayıları, az olanlardan daha fazladır. }\end{array}$ & 41 & 22.98 & $-6,981$ & .000 \\
& Çok & 40 & 59.48 & \\
\hline 5. Geniş bant internet abone sayları daha çok olan illerin & Az & 41 & 23.83 & $-6,650$ & .000
\end{tabular}

internet bankacıliğın kullanan aktif müşteri sayılan, az

olanlardan daha fazladir.

\begin{tabular}{llllll} 
& Çok & 40 & 58.60 & \\
\hline 6. Lise ve üstü eğitimli nüfusu daha çok olan illerin internet & $\mathrm{Az}$ & 41 & 21.39 & $-7,595$ & .000
\end{tabular}

bankacılığını kullanan aktif müşteri sayılant, az olanlardan

daha fazladir.

Çok $\quad 40 \quad 61.10$

Araştırma sonucuna göre sınanan tüm hipotezler için istatistiksel olarak anlamlı sonuçlara ulaşılmıştır. Detaylı tartışma bir sonraki kısımda verilmiştir.

\section{Tartışma ve Sonuç}

Araştırmamızda sanal işyeri sayısı daha çok olan illerin internet bankacıllğını kullanan aktif müşteri sayılarının da çok çıkması e-ticaret kullanmaya yatkın bireylerin internet bankacılı̆̆ını benimsediği görüşünü destekler niteliktedir. Diğer yandan neredeyse tüm işlemlerini çevrim içi yapmaya alışmış ve iş süreçlerini internet ortamına uyarlamış e-ticaret şirketlerinin varlığının da internet bankacıllğına olumlu etki yaptığı kabul edilebilir. Aynı şekilde geniş bant abonelerinin sayısı ve yaygın kullanımdan kaynaklanan aşinalık, her an her dakika internet bağlantısının varlığı gibi nedenler internet üzerinden sunulan diğer hizmetlerin talebini ve kullanımına da etki edebilmektedir. Kimi araştırmacılar e-ticaret hacminin internet kullanım oranıyla yakın ilişkisi olduğunu ve gelişmiş internet altyapısına sahip ülkelerdeki e-ticaret hacminin diğer ülkelere kıyasla daha yüksek olduğunu ileri sürmekteler (İleri ve İleri, 2011). Dolayısıyla geniş bant abone sayısı yüksek olan illerdeki internet bankacılığını kullanan aktif müşteri sayısının da yüksek olması normal kabul edilebilir.

Bilişim-insan etkileşimini araştıran yazında genellikle bu tür teknolojilerin içselleştirilmesinde erkekler lehine sonuçlara sık rastlanmaktadır (Akman, Yazici, Mishra ve Arifoglu, 2005). Özellikle genç nüfusun yeni teknolojilere ve yeniliklere daha açık olduğu varsayılmaktadır (Kim, Widdows ve Yilmazer, 2005). Bulgularımız da bu görüşü destekler niteliktedir. Özellikle eğitimli nüfusun yoğun olduğu illerde hem geniş bant internet abone sayısının çokluğu ve internet bankacıllğını kullanan 
Arslan, A. (2012). İllere ait sosyo-ekonomik ve demografik faktörlerin internet bankacıllğını kullanan aktif müşteri sayılan üzerindeki etkisinin incelenmesi. International Journal of Human Sciences [Online]. (9)2, 288-302.

aktif müşteri sayısının yüksekliği, gizlilik ve güvenlik gibi engellere rağmen, bilinçli bir kullanıcı kitlesinin varlığıyla açıklanabilir.

2011 y1lı itibariyle Türkiye'de internet kullanıcı oranı \% 45’ ulaşmıştır (TÜİK, 2011). Yapılan son araştırmalarda "Facebook" kullanıcı oranında bir düşüş yaşandığı öne sürülse de (http://www. renkliweb.com/teknoloji/internet-teknolojileri/ulkelerin-facebook-kullanicisayisi. html) Türkiye genel nüfusunun yaklaşık \%39,52'si aktif kullanıcıdır ve dünyada yedinci sıradadır. Aynı şeyi internet bankacıllğı (yaklaşık \%22,14) (DT22, 2011) ve e-ticaret kullanım oranı (\%18,6) (Socialmediatr.com, 2011) için söylemek mümkün değildir. İnternet bankacıllğını kullanma oranının, gelişmiş Avrupa ve Asya ülkelerinden daha düşük olsa da gelişmekte olan Asya ülkelerine göre daha yüksek olduğu görülmektedir (Pala ve Kartal, 2010, s.46).

Sonuç olarak bireylerin eğitim ve sosyo-ekonomik gelişmişlik düzeylerinin artması ile internet kullanımının da yaygınlaştığı ve aynı bağlamda internet üzerinden sağlanan hizmetlere olan taleplerin de (internet bankacıllı̆ı) arttı̆̆1 söylenebilir.

\section{Kaynakça}

Adapa, S. (2011). Global E-Banking Trends: Evolution, Challenges and Opportunities. In Mohammad Ali Sarlak and Asghar Abolhasani Hastiani (Eds), E-Banking and Emerging Multidisciplinary Processes: Social, Economical and Organizational Models (pp. 1-16)

Akhlaq, M.A. ve Shah, A. (2011). Internet Banking in Pakistan: Finding Complexities. Journal of Internet Banking and Commerce, 16(1). Retrieved from http://www.arraydev.com/commerce/jibc/2011-04/Akhlaq.pdf.

Akman, I., Yazici, A., Mishra, A. \& Arifoglu, A. (2005). E-Government: A Global View and an Empirical Evaluation of Some Attributes of Citizens. Government Information Quarterly, 22, 239-257. Retreived from http://dx.doi.org/10.1016/j.giq.2004.12.001.

AL-Majali, M. Ve Mat, N.K.N. (2011). Modeling the Antecedents of İnternet Banking Service Adoption (IBSA) in Jordan: A Structural Equation Modeling (SEM) Approach. Journal of Internet Banking and Commerce, 16(1). Retrieved from http://www.arraydev.com/commerce/ jibc/2011-04/MalekAlMajali.pdf.

Altan, M. ve Karasioğlu, F. (2004). Internet Bankacılı̆̆ının Toplum Katmanlarınca Kullanımı Üzerine Bir Araştırma. In Erdemir, E. vd. (Eds), 3. Ulusal Bilgi, Ekonomi ve Yönetim Kongresi Bildiri Kitabr (ss. 25 - 26).

Atay, E. (2008). Macroeconomic Determinants Of Radical Innovations and Internet Banking in Europe. Annales Universitatis Apulensis Series Oeconomica, 2(10), p.4. Retreived from http://oeconomica.uab.ro/upload/lucrari/1020082/4.pdf.

Biswas, S., Taleb, A. ve Shinwary, S.S. (2011). Electronic Banking in Bangladesh: Security Issues, Forms, Opportunities and Challenges. Canadian Journal on Scientific and Industrial Research, 2(5). Retreievd from http://www.ampublisher.com/May \%202011/SIR-1104-015-Electronic-Banking-in-Bangladesh.pdf.

Boyacıŏlu, M.A., Hotamış, T.N. ve Çetin, H. (2010). An Evaluation of Internet Banking in Turkey. Journal of Internet Banking and Commerce, 15(2). Retreived from http://www.arraydev.com/commerce/jibc/2010-08/Boyacioglu.pdf. 
Arslan, A. (2012). İllere ait sosyo-ekonomik ve demografik faktörlerin internet bankacıllğını kullanan aktif müşteri sayılan üzerindeki etkisinin incelenmesi. International Journal of Human Sciences [Online]. (9)2, 288-302.

BTİ (2011). Bilgi toplumu Istatistikleri. Devlet Planlama Teşkilatı Müsteşarlığı, Bilgi Toplumu Dairesi Başkanlı̆̆1, DPT Yayın No: 2826. Retreived from http://www.dpt.gov.tr/ DocObjects/View/12808/Bilgi_Toplumu_Istatistikleri_2011.pdf.

DT22 (2011). Internet ve Mobil Bankaculk İstatistikleri Hað̧ran 2011. Türkiye Bankalar Birliği Raporu. Retreived from http://www.tbb.org.tr.

Gounaris, S. P. ve Koritos, C. D. (2008). Using the Extended Innovation Attributes Framework and Consumer Personal Characteristics as Predictors of Internet Banking Adoption. Journal of Financial Services Marketing, 13(1), pp. 39-51. Retreived from http://www.palgrave-journals.com/ fsm/journal/v13/n1/full/fsm20084a.html.

Gurau, C. (2001). E-banking in transition economies: The case of Romania. Journal of Financial Services Marketing, 6(4), pp.362-378. Retreived from http://tcnh.ntt.edu.vn/ images/banking/32.pdf.

İleri, Y.Y. ve İleri, H. (2011). İnternet Bankacillğı ve E-ticaretin Türkiye Ekonomisi Üzerindeki Etkileri. Selçuk Üniversitesi Sosyal Bilimler Meslek Yülesek. Okulu Dergisi, 14(1-2), pp. 109-125.

IpsosKMG (2010). PC ve Internet Penetrasyon Çalssması. Retreived from http://m.friendfeedmedia.com/ 97ba0b8988c2030c4e8b9ced748b16cc87af244c.

Kang, B. (2009). Information and Communications Technology and Disaster Risk. Reduction Division; Bridging the Digital Divide Between Urban and Rural Areas: Experience of the Republic of Korea. ESCAP Technical Paper, IDD/TP-09-07 (Version 1.0). Retreived from http:// www.unescap. org/idd/working20papers/IDD_TP_09_07_of_WP_ 7_2_911.pdf.

Kim, B., Widdows, R. ve Yilmazer, T. (2005). The Determinants of Consumers'Adoption of Internet Banking. Conference Series Proceedings, Federal Reserve Bank of Boston. Retrevied from http://www.bos.frb.org/news/conf/ payments2005/yilmazer.pdf.

Korkmaz, S. ve Gövdeli, Y. E. (2004). Türk Bankacilığında Alternatif Dağıtım Kanalları ve Ürünleri ile Bunların Gelişiminde ve Pazarlanmasında Eğitimin Önemi. Gą̧i Üniversitesi, Endüstriyel Sanatlar Ë̈̈tim Fakültesi Dergisi, 15. Retreived from http://www.esef.gazi.edu.tr/html/yayinlar/15_pdf/15-a.pdf.

Li, S. ve Worthington, A. C. (2004). The Relationship Between the Adoption of Internet Banking and Electronic Connectivity- An International Comparison. Queensland University of Technology, Discussion papers Series, DP No. 176. Retreived from http://www.bus.qut.edu.au/faculty/schools/economics/documents/discussionPapers/ 2004/DP\%20No.\%20176\%20-\%20Li\%20\%26\%20Worthington.pdf.

Mangin, J.P.L., Bourgault, N. ve Guerrero, M.M. (2011). Modeling Perceived Usefulness on Adopting Online Banking through the TAM Model in a Canadian Banking Environment. Journal of Internet Banking and Commerce, 16(1). Retreived from http://www.arraydev. com/commerce/jibc/ 2011-04/Jean-PierreLevyMangin.pdf.

Mermod, A. Y. (2011). Customer's Perspectives and Risk Issues on E-Banking in Turkey; Should We Still be Online? Journal of Internet Banking and Commerce, 16(1).

Retreived from http://www.arraydev.com/commerce/jibc/2011-04/ YukselMermodAsl. pdf.

Pala, E. ve Kartal, B. (2010). Banka Müşterilerinin internet Bankacıllğı ile İlgili Tutumlarına Yönelik Bir Pilot Araştırma. Yönetim ve Ekonomi, 17(2). Retreived from http://www2. bayar.edu.tr/yonetimekonomi/dergi/pdf/C17S22010/43_61.pdf.

Qurashi, T.M., Zafar, M.K. ve Khan, M.B. (2008). Customer Acceptance of Online Banking in Developing Economies. Journal of Internet Banking and Commerce, 13(1). Retreived from http://www.arraydev.com/commerce/jibc/2008-04/Tahir\%20Masood.pdf.

Reid, M. ve Levy, Y. (2008). Integrating Trust and Computer Self-Efficacy with TAM: An 
Arslan, A. (2012). İllere ait sosyo-ekonomik ve demografik faktörlerin internet bankacıllğını kullanan aktif müşteri sayılan üzerindeki etkisinin incelenmesi. International Journal of Human Sciences [Online]. (9)2, 288-302.

Empirical Assessment of Customers' Acceptance of Banking Information Systems (BIS) in Jamaica. Journal of Internet Banking and Commerce, 12(3). Retreived from http://www.arraydev.com/commerce/jibc/ 2008-12/Levy_JIBCformat.pdf.

Socialmediatr.com (2011). Bilgi Toplumu Istatistikleri 2011 Yaymlandi. Retreived from http://www.socialmediatr.com/blog/bilgi-toplumu-istatistikleri-2011-yayimlandi/.

Sullivan, R. ve Wang, Z. (2005). Internet Banking: An Exploration in Technology Diffusion and Impact. Payments System Research Department Working Paper 05-05, Federal Reserve Bank of Kansas City. Retreived from http://www.kansascityfed.org/publicat/psr/ rwp/IBANK-Sullivan_Wang.pdf.

TNSP (2003). Alternatifi Kim Kullanyor? Capital Online Dergi, 01 Ocak 2003. Retreived from http://www.capital.com.tr/alternatifi-kim-kullaniyor-haberler/15841.aspx.

Toy, B.Y. ve Tosunoğlu, N. G. (2007). Sosyal Bilimler Alanındaki Araştırmalarda Bilimsel Araştırma Süreci, İstatistiksel Teknikler ve Yapılan Hatalar. Ticaret ve Turižm Ë̆itim Fakültesi Dergisi, 2007(1). Retreived from http://www.ttefdergi.gazi.edu.tr/ makaleler/2007/ Sayi1/1-20.pdf.

TÜİK (2011). En son kullanım zamanına göre bireylerin bilgisayar ve İnternet kullanım oranlar1. Retreived from http://www.tuik.gov.tr/PreIstatistikTablo.do?istab_id=41.

Wendy W.N. W., Chung-Leung L. ve Cheris W.C. C. (2005). Customers' Adoption of Banking Channels in Hong Kong. International Journal of Bank Marketing, 23(3), pp.255 - 272.

Retreived from http://www.emeraldinsight.com/journals.htm?issn=0265-

$2323 \&$ volume $=23 \&$ issue $=3 \&$ articleid $=1463456 \&$ show $=$ pdf.

Yentürk, N. Ve Başlevent, C. (2007). “Türkiye'de Genç İşsizliği”, Gençlik Çalışmaları Birimi Araştırma Raporu, No:2, İstanbul Bilgi Üniversitesi Yayını. Retreived from http://www.setav.org/ ups/dosya/10409.pdf.

Yıldız, E. B., Sivri,U. ve Berber, M. (2010). Türkiye'de İllerin Sosyo-Ekonomik Gelişmişlik Sıralaması. Uluslararası Bölgesel Kalkınma Sempozyumu, Bozok Üniversitesi, 07-09 Ekim 2010 (ss.693-705). Retreived from http://www.metinberber.com/kullanici_ dosyalari/ file/ endeks.doc.

\section{Extended English Abstract}

Internet has being used widely in our daily life and in banking sector it is being used as an alternatif service channel (Korkmaz ve Gövdeli, 2004). This enabled banks to offer low cost-high volume service provisions as well as more customer focus, product innovations and variety, enriched marketing and communications, and alternative services that are free from space and time constraints (Mermod, 2011, Pala ve Kartal, 2010, Sullivan ve Wang, 2005). The studies that focus on the use of social media such as Facebook reveal that the Turkish users have reached to 31.112.380 and Turkey has become the 6th in the world usage ranking (http://www.socialbakers.com/facebook-statistics/); however, the number of the individuals that utilize Internet banking is still lower when compared to developed countries (Pala ve Kartal, 2010, Socialmediatr.com, 2011). As of March 2011, the number of individuals that has registered and have accessed to their accounts at least once have reached to a total of 16.3 million customers. This 
Arslan, A. (2012). İllere ait sosyo-ekonomik ve demografik faktörlerin internet bankacilığını kullanan aktif müşteri sayllan üzerindeki etkisinin incelenmesi. International Journal of Human Sciences [Online]. (9)2, 288-302.

is also almost $40 \%$ of the overall banking customers (DT22, 2011). The number of users in some provinces is higher whereas in some there are very few. To explore this discrepancy, and instead of widely used behaviorist models we analyzed panel data. Most of the studies based on behaviorist models are poor in samples which make it hard to generalize.

By reviewing the relevant literature we came up with six hypotheses that may have an impact on the number of Internet banking users; socio-economic development levels of provinces, provinces with more young male population (ages between 15-29), the number of younger individuals at ages between 15-29, the number of online firms in provinces, the number of wideband subscribers in each province, and the number of individuals that received at least high school education and tertiary education.

The data of socio-economic development is adapted from Yildı et al. (2010)'s study. Population statistics are downloaded from Turkish Statistical Institute website. The recent number of broadband subscribers is taken from IpsosKMG (2010) report. And lastly, the number of online firms is found on the Banks Association of Turkey's website database.

The first analysis was to investigate any relationship among the variables. Therefore, a Spearman's rho correlation test was employed. All the independent variables were highly correlated with the dependent variable, active Internet Banking users (See Table 2 below).

Table 2. Correlation Statistics

\begin{tabular}{lllllll}
\hline & $\mathbf{1}$ & $\mathbf{2}$ & $\mathbf{3}$ & $\mathbf{4}$ & $\mathbf{5}$ & $\mathbf{6}$ \\
\hline (1) IB & 1.000 & & & & \\
\hline (2)Socio_eco & $.675^{* *}$ & 1.000 & & & \\
\hline (3) Broadband & $.788^{* *}$ & $.385^{* *}$ & 1000 & & \\
\hline (4) Online_Firms & $.914^{* *}$ & $.685^{* *}$ & $.686^{* *}$ & 1.000 & \\
\hline (5) Age_k30 & $.870^{* *}$ & $.319^{* *}$ & $.814^{* *}$ & $.757^{* *}$ & 1.000 & \\
\hline (6) Edu & $.963^{* *}$ & $.600^{* *}$ & $.818^{* *}$ & $.862^{* *}$ & $.912^{* *}$ & 1000 \\
\hline$\quad N=81 . p<0.01, * *$ & $p<0.05^{*}$ & & & & &
\end{tabular}

As for the hypotheses testing we used Mann-Whitney $U$ non-parametric analyses for two independent variables because the distribution of our data set was not normal. Every data set is divided into two different sets according to their medians. For example the provinces in the first data set were divided into two sets by their lower and higher socio-economic development levels. Additionally the differences of mean ranks were analyzed in order to find whether they were 
Arslan, A. (2012). Illere ait sosyo-ekonomik ve demografik faktörlerin internet bankacilığını kullanan aktif müşteri sayllan üzerindeki etkisinin incelenmesi. International Journal of Human Sciences [Online]. (9)2, 288-302.

statistically significant. According to the results of Mann-Whitney U tests (See Table 3) each of the hypotheses were confirmed significantly.

Table 3 Mann-Whitney U Test Results for Hypotheses (N=81)

\begin{tabular}{cccc}
\hline Statements & $\mathbf{N} \quad \begin{array}{c}\text { Mean Z Score } \\
\text { Rank }\end{array}$ \\
\hline
\end{tabular}

\begin{tabular}{lllllll}
\hline 1. The number of active Internet Banking users of the Lower & 41 & 27.22 & $-5,337$ & .000
\end{tabular}
provinces with higher socio-economic development level is

higher.

\begin{tabular}{llllll} 
Higher & 40 & 55.13 & \\
\hline 2. The number of active Internet Banking users of the Less & 41 & 22.93 & $-7,000$ & .000
\end{tabular}
provinces with more younger male population (ages between 15-29) is higher.

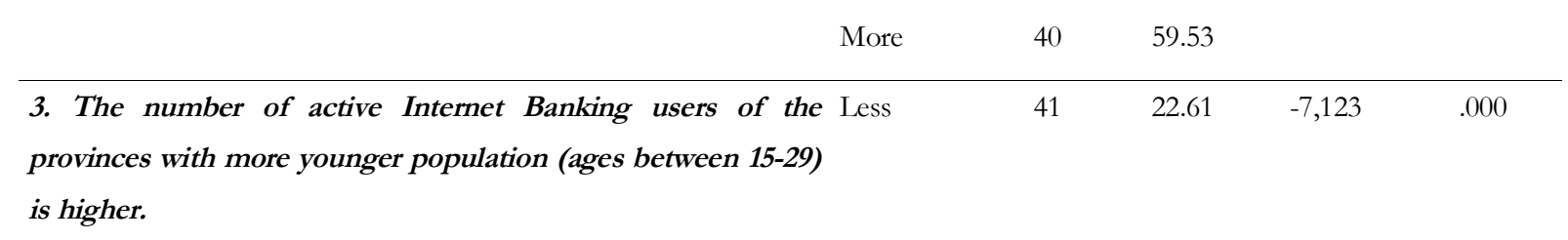

\begin{tabular}{llllll} 
& More & 40 & 59.85 & \\
\hline 4. The number of active Internet Banking users of the Less & 41 & 22.98 & $-6,981$ & .000
\end{tabular}
provinces with more online firms is higher.

\begin{tabular}{lllllll} 
More & 40 & 59.48 & \\
\hline 5. The number of active Internet Banking users of the Less & 41 & 23.83 & $-6,650$ & .000
\end{tabular}
provinces with more broadband subscribers is higher.

\begin{tabular}{|c|c|c|c|c|c|}
\hline & More & 40 & 58.60 & & \\
\hline \multirow[t]{2}{*}{$\begin{array}{l}\text { 6. The number of active Internet Banking users of the } \\
\text { provinces with more high school and tertiary education } \\
\text { graduates is higher. }\end{array}$} & Less & 41 & 21.39 & $-7,595$ & .000 \\
\hline & More & 40 & 61.10 & & \\
\hline
\end{tabular}

As of year 2011, the Internet users in Turkey have reached to 45\% (TÜİ, 2011). However, unlike the Internet user rate Internet Banking $(22,14 \%)$ and e-commerce $(18,6 \%)$ user rates are still low and there is a substantial gap. The results of our research indicate that with the increase of education and socio-economic levels of individuals, a similar increase occurs with the Internet use as well as the demand for Internet services such as the Internet Banking. 